Waste and Resource Management Volume 165 Issue WR4

Recommendations for assessing materials criticality

Lloyd, Lee, Clifton, Elghali and France
Proceedings of the Institution of Civil Engineers

Waste and Resource Management 165

November 2012 Issue WR4

Pages 191-200 http://dx.doi.org/10.1680/warm.12.00002

Paper 1200002

Received 01/03/2012

Accepted 01/05/2012

\title{
Recommendations for assessing materials criticality
}

Stafford Lloyd MEng, AIEMA

Research Engineer, Rolls-Royce, Bristol, UK, and University of Surrey, Guildford, UK

Jacquetta Lee MEng, PhD

Tutor, University of Surrey, Guildford, UK

Andrew Clifton BEng, PhD

Manager, Sustainable Development, Rolls-Royce, Derby, UK
Lucia Elghali MSc, EngD, AIEMA

Senior Lecturer, University of Surrey, Guildford, UK

Chris France MSC, PhD, FRSA

Professor, University of Surrey, Guildford, UK

This paper provides recommendations for assessing the criticality of materials (metals and non-fuel minerals), including the need for context-dependent assessment methods, providing a framework for conducting criticality assessments. Materials criticality captures concerns over the accessibility of materials, as the product of assessing a material's 'supply risk' and the impact of a supply restriction. Through a review of selected studies, problems with criticality assessments are discussed, highlighting how these become particularly important when the results of assessments are used in decision making. Considering how the results of criticality assessments are used in decision making highlights how criticality exhibits some of the characteristics of a 'complex context'. Building on predefined attributes of effective decision support in complex contexts, recommendations are made on how these problems can be addressed to better assess criticality in the future. These also include building on metric-based assessment methods by developing scenarios of future material supply and demand.

\section{Introduction}

Concerns over the availability of materials have resurfaced recently, owing to changes in the demand patterns of raw materials from the emergence of new technologies, developing lifestyles, market dynamics and government policies (Erdmann and Graedel, 2011). The increasing interest in materials criticality is encouraging, as it is an important and complex problem. However, it does have the potential to create confusion over what materials are considered 'critical', or even what term should be used to describe the phenomenon. The purpose of this paper is to provide clarity, by defining the precise problem, the term that should be used to describe it and how it should be assessed. The aim of the paper is not to offer a new methodology for assessing criticality; there are already more than a dozen studies on this aspect (Erdmann and Graedel, 2011) and offering a new approach would only add to the potential for methodological confusion.

Section 2 clearly defines what is meant by 'materials criticality' in an attempt to clarify what the problem is and to settle on a term to describe it. A concise review of selected methods for assessing criticality is given in Section 3, providing a summary of metrics commonly used. The review is used to highlight problems with criticality assessment methods developed to date, and more generally with assessing criticality as described. Section 4 discusses how these problems become particularly important when the results of criticality assessments are used within decision making, highlighting how criticality exhibits some of the characteristics of a 'complex context'. Building on predefined attributes of effective decision support in complex contexts, Section 5 provides recommendations on how criticality can be assessed better in the future, including a framework for completing criticality assessments. Conclusions are given in Section 6.

\section{Materials criticality}

Until the middle of the last decade, concerns over the availability of non-renewable raw materials (metals and non-fuel minerals) focused on the problem of geological scarcity (Erdmann and Graedel, 2011). Efforts to understand the magnitude of the problem applied measurements based on depletion indices (Lee, 1998), which calculated the years of resource remaining by dividing a measure of the amount of resource left by its rate of consumption (Cohen, 2007; Tilton, 2003). Typically, indices used either static values of resources availability or applied dynamic assessments (Alonso et al., 2007).

While this appears to be simple, the problem is significantly more complex, as any estimates of the amount of a resource left contain significant uncertainties. From Gordon et al. (2007), estimates can be based either on resources, reserve base or reserves. Resources are, effectively, the feasibly available amount of a material in the Earth's crust. Reserve base represents resources that are deemed to be extractable with 
current technology. Reserves are the economically extractable parts of the reserve base at current prices. Estimates of reserves and the reserve base are governed by the potential for profitable extraction at any particular time, making the data very unreliable (Gordon et al., 2007).

To a certain extent, these uncertainties have led to a continuing debate on the availability of materials, which remains polarised between those who see depletion as a significant issue and those who have faith in technology and free markets. A view of the main arguments is available from a variety of sources; see for example Tilton (1996), Neumayer (2000), Steen (2006), Tilton and Lagos (2007), Gordon et al. (2007), and Morley and Eatherley (2008).

More recent studies suggest that the debate is moving on, adopting a new perspective and revealing a different problem. As pointed out by Rosenau-Tornow et al. (2009), and others, the question is increasingly becoming one of accessibility rather than availability. Historical examples suggest that the accessibility of resources can be affected by economic, social and environmental constraints as well as geological ones. The 'cobalt crisis' in the 1970s was due to conflict in Zaire (now the Democratic Republic of the Congo), a key supplying region (Alonso et al., 2007). Recent interest in the topic of materials accessibility has been engendered by China dominating supplies of rare earth elements, which geologically are not that rare (National Research Council, 2008). So the question is whether or not the accessibility of resources will be affected by economic, social, environmental and geological constraints and, if so, what might be the consequences.

Presenting what is effectively a risk assessment, materials criticality seeks to understand this problem by assessing the likelihood of a material supply restriction (often termed 'supply risk') and the potential impact if a restriction were to occur. Capturing these two measures neatly in the 'criticality matrix' (Figure 1), a material is considered critical if it is high risk; that is the likelihood of a supply restriction is high and this would have significant negative consequences if it were to occur.

\section{Assessing materials criticality}

Commonly cited reasons for conducting materials criticality assessments include

- increasing and new demand for materials from developing economies

- reliance of developed nations on imported material commodities, which sometimes come from less stable supplying regions

- demand for a wider range of material inputs from new technologies

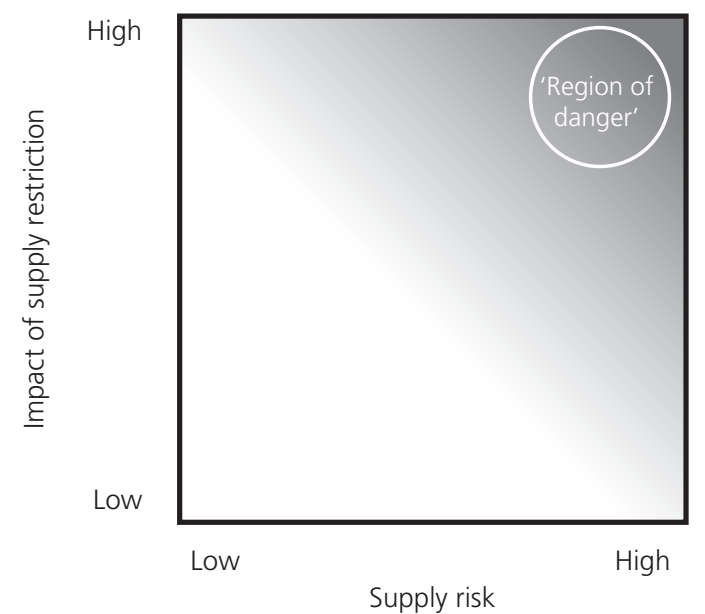

Figure 1. The criticality matrix (National Research Council, 2008)

- recognition of the social and environmental consequences of extraction

- national policy measures that have the potential to disrupt the operation of global markets

- concentrations of production, creating supply monopolies.

Most criticality assessment methods adopt the matrix as a framework, applying metrics to assess supply risk and the impact of a supply restriction, and aggregating the results to identify materials that are considered critical. Metrics for assessing supply risk typically reflect common concerns about why materials might become restricted (as listed), or are derived from factors that in the past have given rise to disruptions in supply, for example political instability in key supplying regions (as in the 'cobalt crisis'). Assessments of impact depend on the context within which the study is being performed, although they can adopt either a global, national or company perspective (Graedel et al., 2012). Aggregation is typically done by translating scores into a common scale, sometimes with weighting factors being applied to highlight the contributions of metrics deemed to be more significant. Results are then plotted on to the matrix to identify critical materials.

A summary review of key criticality assessment methods is presented in Table 1 and discussed in the following subsections. The review is not intended to be exhaustive; an in-depth analysis of the literature is already available (Erdmann and Graedel, 2011). Instead, the purpose is to review selected methodologies to highlight problems with how criticality has been assessed to date and hence what can be done to improve methods in the future. From the numerous studies available for review, five were selected (to provide an overview of the assessment methods developed), on the basis of frequency of citation in the literature (European Commission, 2010 ('EU study'); Morley and Eatherley, 2008 ('Oakedene Hollins study'); National Research 


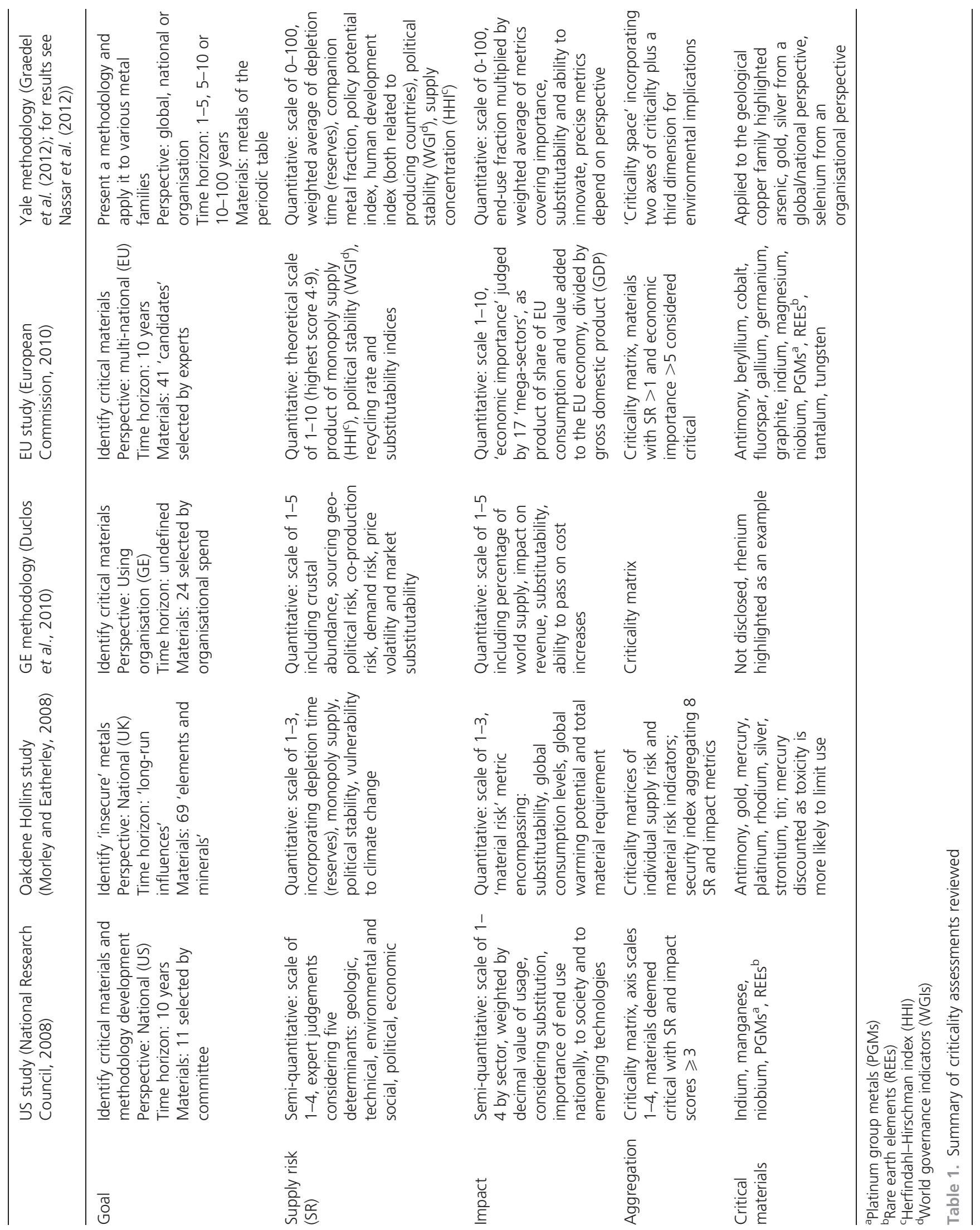


Council, 2008 ('US study') or their relevance to the UK (European Commission, 2010; Morley and Eatherley, 2008). One study was selected as it provides a perspective from a using organisation, General Electric (GE) (Duclos et al., 2010 ('GE methodology'). Another, developed at Yale university, was chosen because it was the most recent and was also deemed to present the most robust methodology developed to date (Graedel et al., 2012 ('Yale methodology'). Three methodologies that only assess supply risk were overlooked (AEA Technology, 2010; BGS, 2011; Rosenau-Tornow et al., 2009), as strictly speaking a material could have a high supply risk and not be critical. Other studies were overlooked either because a version in English was not available or because the studies were not deemed to cover anything not included in those being reviewed.

\subsection{Study goals}

All of the studies reviewed aimed either to identify critical materials and/or to present a methodology that could be used to highlight materials that might be critical. Lists of critical materials are presented by the Oakdene Hollins and EU studies to make recommendations for mitigating actions, which include the need for further investigation and policies to mitigate potential supply restrictions. The GE study researchers sought to use their methodology to identify steps that can be taken to mitigate the risks. The US study was more hesitant, explicitly stating that its goal was not to offer a discrete list of critical materials, as it was only a preliminary study. Its position on not developing a critical materials list highlights how uncertainties in assessments require caution when results are used within decision making, which supports later discussion.

All of the studies adopted a slightly different perspective, time horizon or focused on different materials. The perspective depends on the system under study, which, in turn, will influence the materials selected. Time horizons were selected to strike a balance; too short and it can be difficult to separate short-term supply and demand fluctuations from what might be more fundamental problems with accessibility. Too long and it becomes almost impossible to predict problems with any degree of certainty. Both the US and Yale studies suggest that the nature of the assessment should depend on the time horizon adopted.

\subsection{Supply risk, impact and aggregation}

Each of the reports reviewed applied a different set of metrics for measuring supply risk and impact, aggregating them in different ways. The following subsections review the main methodological considerations.

\subsubsection{Supply risk}

Most reports covered all of the five determinants initially identified by the US study in assessing supply risk: geological, technical, political, environmental and social, and economic.
Geological measures were explicitly excluded by the EU study, being deemed unreliable in predicting long-term availability and irrelevant in the short to medium term. Morley and Eatherley (2008) also considered geological measures of secondary importance owing to their uncertainty. Caution should certainly be applied when using geological measures within criticality assessments (Lloyd et al., 2011), although they should not necessarily be excluded. Graedel et al. (2012) suggest that depletion times give a useful indication of the current relationship between supply and demand, and viewed in this way they are a useful measure. In the longer term (more than 10 years), economic and social factors become very difficult to predict and Graedel et al. (2012) suggest that only geological measures for assessing supply risk should be used in this timeframe, combining reserve base estimates with component metal fraction. Component metal fraction, or 'coproduction risk' as described in the GE method, reflects the fact that some materials are produced from traces within the ore of a 'host' metal. For example, hafnium is largely produced as a co-product of zirconium, which comes primarily from titanium ores. As a co-product, the supply of material is governed by demand for its host, not for the material itself, so there is no guarantee that supply will change if demand does. Discussions with commodity experts suggested that co-production is a valid and important indicator of supply risk.

Monopoly supply was a metric adopted by all studies as a clear indicator of potential material supply restrictions. The most popular, and probably most robust, means of assessing monopoly supply is the Herfindahl-Hirschman index (HHI), which, in its simplest form, is the sum of the squares of the supply percentages of producing countries, producing a theoretical value of between 0 and 10000 . (For example, if $40 \%$ of material $\mathrm{X}$ is produced in country A, $40 \%$ in country B and $20 \%$ in country C, the HHI would be $40^{2}+40^{2}+20^{2}=3600$. A higher HHI score indicates a greater risk of supply restrictions.) This value is usually adjusted to reflect the scoring scheme applied by an assessment. While this is a relatively simple measure, it is still necessary to decide the level of supply concentrations that should give cause for concern. Alonso et al. (2007) suggest that high levels of concern exist when market shares reach $40 \%$. A HHI of 1800 is considered problematic by the US Department of Justice (Graedel et al., 2012). Monopoly supply conditions become more of a concern when concentrations occur in less stable regions, so studies tend to merge HHI scores (or other measures of supply diversity) with an assessment of political stability. Two prominent indices are the world governance indicators (WGIs) (Kaufmann et al., 2010) and the failed states index (FSI) (Messner, 2011). Both analyse a variety of social indicators to produce scores indicating politically stability. As with the HHI, these scores are usually manipulated to be consistent with the scoring scheme used by an assessment. Given the WGI and FSI are both 
single scores aggregated from a wide variety of metrics, further manipulation could create meaningless numbers.

Other popular factors for assessing supply risk include recycling rate, substitutability, price volatility, demand changes, and environmental and social indicators. Availability of secondary (i.e. recycled) materials reduces dependence on primary production, hence reducing the risk of supply disruptions. Economic data on recycling rates were used in the EU report, presented by material as a decimal. Improved data on the percentage recycling rates of materials have now been developed (Graedel et al., 2011).

Substitutability appears in both the measures of supply risk and impact. As a factor of supply risk it considers all uses of a material. If the material lacks substitutability in all or the majority of its applications, restrictions in supply will be emphasised as mitigating options will be limited. In the EU report substitutability was presented as a decimal similar to recycling rates, determined through expert judgement. Other methodologies included it as an impact metric. Price volatility is a useful indicator of supply risk in the short to medium term, as price fluctuations in a material could indicate underlying market dynamics that could lead to supply restrictions. Volatility is often measured as a ratio of maximum to minimum price for a material over a set time period (10 years is common). Demand changes are generally included as new applications create competing uses for a material, potentially restricting supply, in particular if production cannot be increased to meet demand, for example for materials produced as a coproduct.

Environmental and social indicators reflect the fact that these impacts can inhibit (or in the case of social measures, sometimes encourage) primary production. It is considered that environmental limitations are more likely to restrict supply than physical scarcity (Morley and Eatherley, 2008). Many environmental and social metrics can be used and can either be aggregated within an assessment of supply risk, as used in the GE, Oakdene Hollins and US studies, or considered separately, as used in the EU report and the Yale methodology. The EU report applied an additional environmental country risk metric, based on a policy performance rating system (coincidentally also developed by Yale University) applying a distance-to-target approach. The logic is that the further a country is from stated environmental policy goals, the more likely it is to restrict production of materials. Other environmental measures usually apply proxies, such as total material requirement or global warming potential (in carbon dioxide equivalents) measured per kilogramme of material produced. Indices such as the human development index (HDI) can be applied to highlight the presence of social issues within producing countries.
A summary of the various metrics typically used to assess supply risk is provided in Table 2, along with their underlying assumptions.

\subsubsection{Impact}

Measurements of impact are inevitably context dependent and the metrics used typically depend on the perspective of a study. From the perspective of a using organisation, the focus is on the materials that are critical to meeting objectives, whether these are commercial or related to fulfilling critical functions (for example within the military or medical industries); rhenium was highlighted as an issue by GE owing to its importance in the manufacture of gas turbine engines. Metrics tend to focus on issues such as the ease of substitutability, price volatility and potential impact on revenue and product costs.

National perspectives focus more on importance to the economy, as reflected in the EU study, also including factors such as substitutability and environmental impacts. From a global perspective, suggested indicators include importance to using populations and environmental metrics, as well as ease of substitutability. A longer-term focus is also required from a

\begin{tabular}{|c|c|}
\hline Supply risk metric & Underlying assumption \\
\hline $\begin{array}{l}\text { Geological measures (depletion } \\
\text { indices or abundance) }\end{array}$ & $\begin{array}{l}\text { Low depletion index/ } \\
\text { abundance increases risk }\end{array}$ \\
\hline Co-production & $\begin{array}{l}\text { Primary ore dependence } \\
\text { increases risk }\end{array}$ \\
\hline Monopoly supply & $\begin{array}{l}\text { Supply concentrations } \\
\text { increase risk }\end{array}$ \\
\hline Political stability & $\begin{array}{l}\text { Instability in producing } \\
\text { regions increases risk }\end{array}$ \\
\hline Recyclability & $\begin{array}{l}\text { Lack of recycled sources } \\
\text { increases risk }\end{array}$ \\
\hline Substitutability & $\begin{array}{l}\text { Lack of substitutability } \\
\text { increases risk }\end{array}$ \\
\hline Environmental impact & $\begin{array}{l}\text { High environmental } \\
\text { impacts increase risk }\end{array}$ \\
\hline Demand changes & New demand increases risk \\
\hline Price volatility & $\begin{array}{l}\text { High price volatility } \\
\text { increases risk }\end{array}$ \\
\hline Social impact & $\begin{array}{l}\text { Presence of social issues } \\
\text { increases risk }\end{array}$ \\
\hline
\end{tabular}

Table 2. Summary of supply risk metrics and underlying assumptions 
global perspective. Graedel et al. (2012) present a comprehensive set of metrics for addressing impact from each perspective, summarised in Table 3.

\subsubsection{Aggregation}

Aggregation is a multi-criteria problem, requiring the need to capture judgements on how a wide-ranging set of indicators and sources of information can be brought together in a meaningful way to highlight critical materials. Combining measures requires translating metrics into a common scale, including weighting factors (if required) to highlight the contributions of metrics deemed to be more significant. Judgements are required to determine the level at which concern should be raised for metrics on their own and when combined within the criticality matrix.

\begin{tabular}{|c|c|c|}
\hline Perspective & Components & Indicators \\
\hline \multirow[t]{3}{*}{ Organisation } & Importance & $\begin{array}{l}\text { Percentage of revenue } \\
\text { impacted } \\
\text { Ability to pass through cost } \\
\text { increases } \\
\text { Importance to corporate } \\
\text { strategy }\end{array}$ \\
\hline & Substitutability & $\begin{array}{l}\text { Substitute performance } \\
\text { Substitute availability } \\
\text { Environmental impact ratio } \\
\text { Price ratio }\end{array}$ \\
\hline & $\begin{array}{l}\text { Ability to } \\
\text { innovate }\end{array}$ & Corporate innovation \\
\hline \multirow[t]{3}{*}{ National } & Importance & $\begin{array}{l}\text { National economic } \\
\text { importance } \\
\text { Percentage of population } \\
\text { utilising }\end{array}$ \\
\hline & Substitutability & $\begin{array}{l}\text { Substitute performance } \\
\text { Substitute availability } \\
\text { Environmental impact ratio } \\
\text { Net import reliance ratio }\end{array}$ \\
\hline & Susceptibility & $\begin{array}{l}\text { Net import reliance } \\
\text { Global innovation index }\end{array}$ \\
\hline \multirow[t]{2}{*}{ Global } & Importance & $\begin{array}{l}\text { Percentage of population } \\
\text { utilising }\end{array}$ \\
\hline & Substitutability & $\begin{array}{l}\text { Substitute performance } \\
\text { Substitute availability } \\
\text { Environmental impact ratio }\end{array}$ \\
\hline
\end{tabular}

Table 3. Metrics for assessing the impact of a supply restriction (Graedel et al., 2012)
All assessment methods applied different methods for aggregating metrics to give scores of supply risk and impact, in turn, using different matrices to assess criticality. Very few studies justify the aggregation approach, either in terms of how common scales were developed or boundaries of significance chosen, providing very little transparency on the reasoning behind decisions made. This makes the results difficult to defend as a robust assessment. It might be the case that aggregation in some studies is governed more by the need for ease of numerical manipulation, rather than analytical rigour, which would lead to more robust results (Erdmann and Graedel, 2011).

\subsection{Problems with criticality assessments}

There are several problems with some of the criticality assessment methods reviewed and more generally with assessing criticality as described. It is clear that assessments of criticality depend upon subjective judgements, at various levels. Metrics used to assess supply risk and impact are inevitably influenced by the perspective of the system being studied, materials being assessed and the time horizon. Some metrics themselves may be dependent on subjective interpretations, for example substitutability. Value judgements are also implicit in any weightings used to highlight metrics that are more or less significant, how the metrics are aggregated and where boundaries of significance are set to identify materials that are more or less critical. It is inevitable that different studies will arrive at different results and these subjectivities make it unlikely that the results of any one assessment method can be universally applied.

Criticality assessments also contain significant sources of uncertainty, which are rarely addressed. Results of an assessment are often dependent on the aggregation of diffuse metrics, derived from incomplete data or qualitative judgements. Applying aggregation methods means that small changes in underlying metrics, which are inherently uncertain, can significantly influence results (Erdmann and Graedel, 2011; Lloyd et al., 2011). From the assessment methods reviewed, only the Yale method addressed uncertainty. The suggested approach was to conduct Monte Carlo simulations using distributions modelling variations in metrics, tracking how these affect key results when aggregated (Graedel et al., 2012).

In all assessments uncertainties need at least to be acknowledged, or better, understood to some extent through suitable analysis. At the least, methodologies should be developed iteratively, reviewing initial results and adjusting the methods appropriately to ensure they reflect underlying concerns. However, all studies lack explanation of how the underlying methodological choices lead to the results obtained and whether or not they are appropriate.

As discussed in the critique of aggregation methods, there is also a lack of transparency within assessment methods. All 
studies and methodologies are dependent on decisions regarding the metrics to be used, how they are aggregated and how critical materials are identified. However, most offer little justification for the methodological choices made. Organisations concerned about critical materials will want to run their own assessments, although even to begin with it is often very difficult to take an existing study and re-create results.

Data challenges present further difficulties for conducting criticality assessments. Data can be difficult to obtain in the first place, for example production data on co-products may be privately held. Indices for providing an indication of political stability, or databases containing information on the environmental impacts of production, may be proprietary and lack transparency. Disagreements between sources of data are also not uncommon, for example discrepancies between production data compiled by different national geological surveys. Managing the sheer amount of data required can represent a challenge in itself, especially if information needs to be updated on an annual basis.

A further problem, which is often overlooked, is that some of the methodological decisions are influenced by past events. Selecting metrics is often done on the basis of what has historically caused supply disruptions. Some metrics are actually records of past data (e.g. price volatility). Judgements on boundaries of significance can also be dependent on what has caused problems in the past (e.g. levels of supply concentration). Criticality assessments should seek to look into the future, and experience suggests that using historical precedents is a poor means of doing so (Taleb et al., 2009).

\section{Implications for decision making}

Some of these problems are inevitable and most studies acknowledge that the nature of criticality assessments will differ, depending on who they are developed by and for what purpose. The EU study noted the diverse outcomes from assessments performed at a national level by member states, in particular how differences in national economies affected perceptions of economic importance. Subjectivities are also acknowledged within the Yale methodology, which explicitly seeks to 'permit flexibility by the user in its application' (Graedel et al., 2012). However, these problems tend to be overlooked when they become important, which is when the results of criticality assessments are used to agree mitigating actions, whether at an organisational, industry, national or supranational level (for example the EU). There is a perceived tendency to create lists of critical materials and apply them to mitigate risks unilaterally, with little consideration for the suitability of the methods that have derived them and what the implications of this might be for materials that may actually be more or less critical.
Lack of consideration for the context-dependent and uncertain nature of criticality assessments within decision making could lead to the incorrect signals and behaviours. The authors have seen examples of policy actions made using criticality lists, which do not reflect the concerns of a particular organisation or even industry. It is very unlikely that de facto lists of critical materials can be simply developed and applied to mitigate all risks, as the value-laden nature of assessment methods means that a universal set of critical materials cannot be developed. Criticality is far too much of a complex problem to be addressed in this way, although considering complexity does lead to some potential solutions to these problems.

Considering how the results of criticality assessments are used in decision making highlights how criticality exhibits some of the characteristics of a 'complex context', discussed by Elghali et al. (2008) as a common feature of decisions that involve evaluations related to sustainability. In particular, materials criticality (from Elghali et al., 2008)

n is characterised by a dynamic system of problems with emergent properties that could not be produced by one part of the system alone

- involves social aspects that need to be adequately considered alongside technical ones

- requires different interpretations of the problem dependent on the context

- has a degree of 'post-normality', where values guide outcomes as well as scientific certainty.

Elghali et al. (2008) also identify attributes of effective decision support in complex contexts, stating that any approach, among other things, must

- explicitly include considerations for uncertainty arising from incomplete information

- involve all relevant stakeholders within decision making, in particular those who can provide first-hand experience of a problem

- recognise multiple criteria and how they contribute to an assessment

- be adaptable to changing situations and outcomes, providing an audit trail of decisions made and why.

\section{Recommendations for assessing criticality}

Building on these attributes of effective decision support in complex contexts, the following recommendations are made to improve assessing materials criticality in the future.

Reflecting the need to explicitly include uncertainty and recognise multiple criteria, criticality assessments need to provide a transparent view of how results are affected by methodological choices and uncertainties in underlying metrics, which also need 
to be appropriately acknowledged within decision making to determine any mitigating actions. Assessments should also be accompanied by a discussion of how the methods chosen have led to the results obtained and whether or not they are sensible given underlying concerns. For example, if a material is highlighted as critical owing to its geological scarcity, but because of inherent uncertainties in the data this is considered of secondary importance, one action could be to alter the assessment method with a lower weighting for geological metrics.

To involve all relevant stakeholders and be adaptable to changing situations, and acknowledging the subjectivities of criticality, context-dependent assessment methods are required, developed through the use of a stakeholder community. Such a community should include those with first-hand experiences of the problem, for example purchasing professionals. It would be impractical if every organisation performed its own assessment and acted unilaterally to mitigate any risks identified from materials highlighted as critical. However, it is also not possible to develop a global or even national list of critical materials that can be used by everyone. Balance is required between practicality and possibility and it is suggested that performing assessments at the level of an industry sector might provide such a balance. It is likely that companies in the same industry will use the same materials and share concerns over what could cause restrictions in accessibility. Being in the same industry it is also likely that organisations collaborate on other issues, in particular when it comes to influencing policy on, for example, national research funding. Industry groups could be developed that include the necessary stakeholder representation, agreeing a joint assessment method.

To facilitate context-dependent assessments, a transparent, peer-reviewed open-source database of metrics to support criticality assessments is required, incorporating measures of uncertainty. These need to cover the variety of measures required to measure both supply risk and impact, summarised in Tables 2 and 3, drawing information from a variety of sources, for example

- national geological surveys, providing data on geological measures, production and co-product risks

- organisations that produce political stability and social indicators, such as the world governance and human development indices

- economic data, in particular on price volatility and supply and demand patterns

- databases providing information on the environmental impacts of material production.

Alongside metrics, a framework for criticality assessments is required. An example of such a framework is provided in Figure 2, identifying the main steps within an assessment and

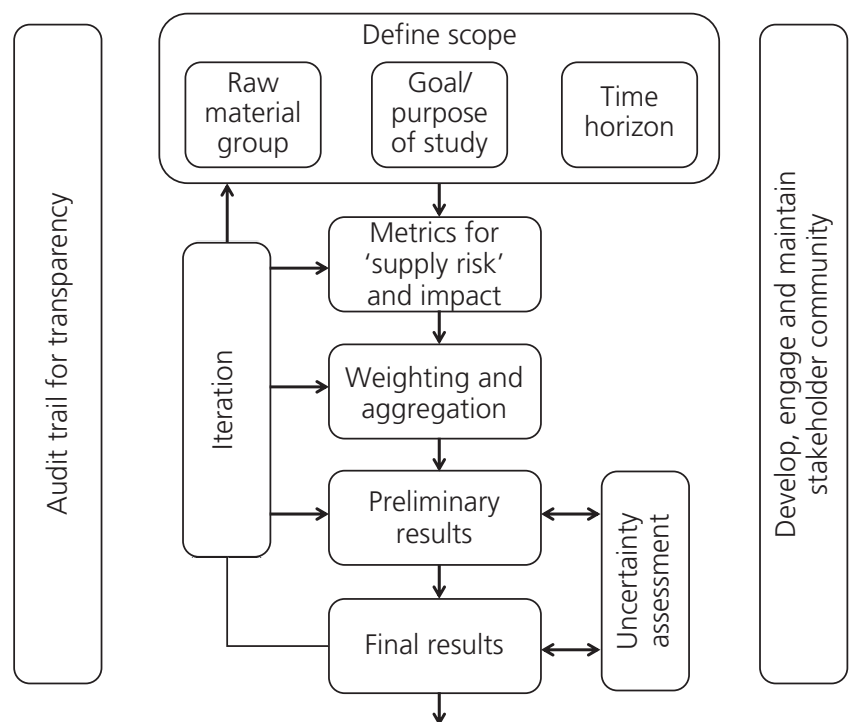

Figure 2. Framework for criticality assessment

highlighting the importance of considering iteration, uncertainty, transparency and engaging with a stakeholder community. Criticality is a dynamic problem, so it is also recommended to update assessments on a regular basis, perhaps annually, to highlight materials that may have become more or less critical.

Finally, it is recommended to build upon criticality assessments that rely on the use of metrics by developing scenarios of supply and demand, to overcome reliance on historical precedents. It should be made clear that scenarios do not seek to predict the future, as this is impossible to do with any degree of certainty (Sohn, 2006). Instead, scenarios seek to develop 'consistent and plausible pictures of possible future realities' (Lempert et al., 2009).

Several studies have already attempted to construct scenarios of material supply and demand; see for example Alonso et al. (2012), Gruber et al. (2011), Kleijn and van der Voet (2010) and Yang (2009). All of these studies attempt to analyse what might happen in terms of material supply and how new technologies and demographics may change demand, analysing implications for materials availability. With such a complex problem, it is inevitably difficult to model changes in material supply patterns and how innovation and demographics may affect demand. However, producing scenarios does provide a more in-depth understanding of the dynamics of material supply systems and hence where restrictions may occur, particularly in the longer term. Some scenario studies do have a tendency to focus on basic measurements of resource quantities, re-focusing on availability, rather than accessibility, as discussed previously. More robust scenarios would seek to capture potential problems in both availability and accessibility. 
As scenarios are just a possibility, they should be treated with care. Convergence between scenarios on materials that are more or less critical could indicate a higher likelihood of longterm problems. One approach could be to use criticality assessments for initial screening, highlighting materials for which a more in-depth scenario analysis would be beneficial.

\section{Conclusions}

Materials criticality is a complex problem that has only become a topic of serious interest in the last 5 years. Given this complexity, limitations in assessment methods are inevitable and most of the problems highlighted in this paper have been acknowledged in previous studies and reports. However, from the authors' experiences, where these problems tend to be overlooked is when the results of criticality assessments are used in decision making, which is also when they become the most important. Not addressing these problems could lead to the wrong signals and behaviours, potentially increasing the risks posed to businesses and the economy instead of mitigating them.

Through drawing on attributes of decision support in complex contexts, this paper has made recommendations on how these problems can be overcome, including the following points.

- Transparency should be provided within assessment methods so it is clear how the methodological choices made have led to the results obtained and whether or not they are appropriate. This includes incorporating considerations for uncertainty, in particular when results are applied for decision making.

- Context-dependent assessment methods should be developed through stakeholder communities, including those who have first-hand experiences of the problem. To complete assessments, databases of metrics are required, alongside guidance on how criticality assessments should be conducted, for which a framework for criticality assessments has been provided.

- It is necessary to build on metric-based assessment methods by developing scenarios of future material supply and demand.

Implementing these recommendations will not be easy, although the problem of materials criticality deserves significantly more attention if businesses and the economy are to become more sustainable in the long term.

\section{Acknowledgements}

This paper was completed as part of an Engineering Doctorate project at the University of Surrey Centre for Environmental Strategy, co-sponsored by Rolls-Royce with support from the Samulet (Strategic Affordable Manufacturing in the UK through Leading Environmental Technologies) programme. Financial support from the Engineering and Physical Science
Research Council and the Technology Strategy Board is acknowledged.

Conversations with the following people (in alphabetical order) have contributed significantly to the authors' views on materials criticality: Conny Bakker, Andrew Bloodworth, Roland Clift, James Goddin, Thomas Graedel, Andrew 'Gus' Gunn, Paul Lusty, Kim Marshall, David Peck, Jim Petrie and Simon Ryder.

\section{REFERENCES}

AEA Technology (2010) Review of the Future Resource Risks Faced by UK Businesses and an Assessment of Future Viability. Department for Environment, Food and Rural Affairs (Defra), London, UK.

Alonso E, Gregory J, Field F and Kirchain R (2007) Material availability and the supply chain: Risks, effects and responses. Environmental Science and Technology 41(19): 6649-6656.

Alonso E, Sherman AM, Wallington T et al. (2012) Evaluating rare earth element availability: A case with revolutionary demand from clean technologies. Environmental Science and Technology 46(6): 3406-3414.

BGS (2011) Risk List 2011. BGS, Keyworth, UK, see www. bgs.ac.uk/mineralsuk/statistics/riskList.html (accessed 14/09/2011).

Cohen D (2007) Earth audit. New Scientist 194(2605): 34-41.

Duclos SJ, Otto JP and Konitzer DG (2010) Design in an era of constrained resources. Mechanical Engineering 132(9): 36-40.

Elghali L, Clift R, Begg KG and McLaren S (2008) Decision support methodology for complex contexts. Proceedings of the Institution of Civil Engineers - Engineering Sustainability 161(1): 7-22.

Erdmann L and Graedel TE (2011) Criticality of non-fuel minerals: A review of major approaches and analyses. Environmental Science and Technology 45(18): 7620-7630.

European Commission (2010) Critical Raw Materials for the $E U$. European Commission, Brussels, Belgium.

Gordon RB, Bertram M and Graedel TE (2007) On the sustainability of metal supplies: A response to Tilton and Lagos. Resources Policy 32(1-2): 24-28.

Graedel TE, Allwood J, Birat JP et al. (2011) What do we know about metal recycling rates? Journal of Industrial Ecology 15(3): 355-366.

Graedel TE, Barr RM, Chandler C et al. (2012) Methodology of metal criticality determination. Environmental Science and Technology 46(2): 1063-1070.

Gruber PW, Medina PA, Keoleian GA et al. (2011) Global lithium availability: A constraint for electric vehicles? Journal of Industrial Ecology 15(5): 760-775.

Kaufmann D, Kraay A and Mastruzzi M (2010) The Worldwide Governance Indicators. World Bank, Washington, D.C., USA, Policy Research Paper 5430. 
Kleijn R and van der Voet E (2010) Resource constraints in a hydrogen economy based on renewable energy sources: An exploration. Renewable and Sustainable Energy Reviews 14(9): 2784-2795.

Lee CH (1998) Formulation of resource depletion index. Resources, Conservation and Recycling 24(3-4): 285-298.

Lempert R, Hallsworth M, Hoorens S and Ling T (2009) Looking Back on Looking Forwards: A Review of Evaluative Scenario Literature. European Environment Agency, Copenhagen, Denmark.

Lloyd S, Lee J, Clifton A, Elghali L and France C (2011) The likelihood of restrictions in the availability of metallic resources. Proceedings of the 2011 Engineering Doctorate Conference, University of Surrey, Guildford, UK, pp. 283-297.

Messner JJ (ed.) (2011) Failed States Index 2011. The Fund for Peace, Washington, DC, USA.

Morley N and Eatherley D (2008) Materials Security: Ensuring Resource Availability for the UK economy. C-Tech Innovation Ltd, Chester, UK.

Nassar N, Barr R, Browning M et al. (2012) Criticality of the geological copper family. Environmental Science and Technology 46(2): 1071-1078.

National Research Council (2008) Minerals, Critical Minerals and the U.S. Economy. National Academies Press, Washington, DC, USA.
Neumayer E (2000) Scarce or abundant? The economics of natural resource availability. Journal of Economic Surveys 14(3): 307-335.

Rosenau-Tornow D, Buchholz P, Riemann A and Wagner M (2009) Assessing the long-term supply risks for mineral raw materials - a combined evaluation of past and future trends. Resources Policy 34(4): 161-175.

Sohn I (2006) Long term projections of non-fuel minerals: we were wrong, but why? Resources Policy 30(4): 259-284.

Steen BA (2006) Abiotic resource depletion: Different perceptions of the problem with mineral deposits. International Journal of Life Cycle Assessment 11(1): 49-54.

Taleb NN, Goldstein DG and Spitznagel MW (2009) The six mistakes executives make in risk management. Harvard Business Review 87(10): 78-81.

Tilton JE (1996) Exhaustible resources and sustainable development. Resources Policy 22(1/2): 91-97.

Tilton JE (2003) On Borrowed Time? Assessing the Threat of Mineral Depletion. Resources for the Future, Washington, DC, USA.

Tilton JE and Lagos G (2007) Assessing the long-run availability of copper. Resources Policy 32(1-2): 19-23.

Yang CJ (2009) An impending platinum crisis and its implications for the future of the automobile. Energy Policy 37(5): 1805-1808.

\section{WHAT DO YOU THINK?}

To discuss this paper, please email up to 500 words to the editor at journals@ice.org.uk. Your contribution will be forwarded to the author(s) for a reply and, if considered appropriate by the editorial panel, will be published as a discussion in a future issue of the journal.

Proceedings journals rely entirely on contributions sent in by civil engineering professionals, academics and students. Papers should be $2000-5000$ words long (briefing papers should be 1000-2000 words long), with adequate illustrations and references. You can submit your paper online via www.icevirtuallibrary.com/content/journals, where you will also find detailed author guidelines. 